\title{
RENAL INVOLVEMENT IN VISCERAL LEISHMANIASIS DOGS
}

\section{SOARES M. J. V. (1), MORAES J. R. E. (1), PALMEIRA BORGES V. (1), MIYAZATO L. G. (1), MORAES F. R. (1)}

(1) Department of Veterinary Pathology (DPVE), School of Agrarian and Veterinary Sciences (FCAV), São Paulo State University (UNESP), Jaboticabal, São Paulo, Brazil.

\begin{abstract}
Visceral leishmaniasis (VL) is a zoonosis that affects both animals and man. Dogs are the etiological agent's main reservoir. The aim of this study was to evaluate the clinical laboratory aspects and renal histopathology of VL dogs. Thirtyfour symptomatic (case) and 17 asymptomatic (control) VL seropositive dogs of different breeds, sexes, and ages from Teresina, Piauí State, Brazil, were used. Diagnosis was confirmed by enzyme-linked immunosorbent assay and indirect immunofluorescence test. Clinical and laboratory tests included blood cell count and renal function analysis (urea and creatinine). Animals were subjected to euthanasia and necropsy. Renal fragments were prepared by the usual histological techniques and stained with hematoxylin-eosin and periodic acid-Schiff. Physical examination showed that lymph node hypertrophy (85.29\%) and skin lesions (35.29\%) were frequent in the case group. Anemia was found in $55.88 \%$ of the case and in $11.76 \%$ of the control group. There was a significant difference between groups by Fisher's exact test. Two case-group dogs showed azotemia. Renal histopathological evaluation showed that $61.76 \%$ case and $17.65 \%$ control-group dogs had membranoproliferative glomerulonephritis. Mesangial proliferative glomerulonephritis was seen in $32.35 \%$ case and $64.70 \%$ control-group animals. There was a significant difference for both types of glomerulonephritis between groups. Amastigote forms of Leishmania were found in the renal parenchyma, in the inflammatory infiltrate of one case-group dog. We concluded that, in canine VL, regardless of the clinical signs at physical examination, the kidneys are frequently compromised.
\end{abstract}

KEY WORDS: dogs, kala-azar, Leishmania, renal lesion.

\section{CORRESPONDENCE TO:}

JULIETA RODINI ENGRÁCIA DE MORAES, Laboratório de Patologia Experimental e Comparada, Departamento de Patologia Veterinária, FCAV-UNESP, Via de Acesso Professor Paulo Donato Castellani, Km 5, 14884-900, Jaboticabal, SP, Brasil. Phone: 0163209 2662. Email: jrmoraes@fcav.unesp.br. 


\section{INTRODUCTION}

Visceral leishmaniasis (VL) is a zoonosis that affects both animals and man. Transmission occurs in wild, rural and urban areas in and around the houses. It is a rapidly spreading endemic disease in Brazil and is caused by the protozoan Leishmania chagasi. Dogs (Canis familiaris) and foxes (Dusicyon vetulus) are its major reservoirs, and transmission is by the female Lutzomyia longipalpis, a hematophagous insect (3).

In general, VL clinical features in dogs are similar to those of man with irregular fever, paleness of the mucous membrane and progressive weight loss until intense terminal cachexia. Hypertrophy of the mononuclear phagocytic system, leading to splenomegaly, hepatomegaly, and general adenopathy, is frequent. However, the most evident signs are related to cutaneous and hair alterations: general or focal hair loss; isolated or confluent small scabby ulcerations on the muzzle and ear extremities; furfuraceous desquamation or dermatitis; onychogryphosis; intersticial keratitis after purulent conjuntivitis; apathy; diarrhea; intestinal hemorrhage; pelvic limb paresis; edema; and vomiting (14).

Canine VL laboratory alterations are similar to those of man. Normochronic anemia is frequent (62\%) while moderate leukopenia is less frequent (7).

Anemia occurs due to blood loss, red blood cell lysis or, more frequently, to decreased erythropoiesis resulting from medullar hypoplasia or aplasia (10).

Normocytic normochromic anemia was found in $60 \%$ of 150 dogs naturally infected with VL (5).

Non-regenerative anemia was common in a study of 95 canine leishmaniasis cases. Leukocytosis was rare (8\%), and leukopenia occurred in $22 \%$ cases. There was a slight left shift of the neutrophilic series in $19 \%$ of the dogs. Lymphopenia was seen in $42 \%$ of the cases and lymphocytosis was present in only one patient (24). Leukocytosis with neutrophilic left shift is common in VL dogs (23).

Thrombocytopenia was identified in $50 \%$ of the animals in a study on 95 canine leishmaniasis cases (24) and in $29.3 \%$ of 150 dogs with the same disease (5).

There may be no difference in platelet count between control and leishmaniasis dogs (15). Epistaxis is common and generally unilateral, it is caused by ulcerous lesions in the nasal mucosa and/or alterations in coagulation due to hyperglobulinemia and thrombocytopenia (18). 
Leishmania donovani amastigotes have rarely been identified in neutrophils of dogs with disseminated leishmaniasis (23). Leishmania parasites have been detected only once in monocytes from a blood smear (24).

Proteinuria is frequently observed in glomerular diseases and reflects increase in the glomerular capillary permeability to plasma proteins, especially albumin (glomerular proteinuria) (2). In all types of membranoproliferative glomerulonephritis, the urine test usually shows proteinuria and hematuria (12). Nephrotic syndrome and uremia are the causes of death of leishmaniasis dogs. In many cases, death is caused by acute renal failure without other signs of the disease (18).

Based on the World Health Organization (WHO) classification criteria of glomerulonephritis (4), the main morphological glomerular alterations are: membranous glomerulonephritis, crescentic glomerulonephritis, membranoproliferative glomerulonephritis, focal segmental sclerosis, total sclerosis, mesangial proliferative glomerulonephritis, and chronic glomerulonephritis.

Membranous glomerulonephritis is characterized by a diffuse thickening of the basal glomerular membrane due to subepithelial and/or intramembranous electron dense deposits, which, by immunofluorescence microscopy, represent IgG and $\mathrm{C}_{3}$ diffuse deposits with granular pattern in the capillary loops. There is also membrane neoformation with collagen and glycoprotein deposits incorporated to the basal membrane deposits, but the glomerular architecture is commonly preserved with normal cellularity containing slightly dilated capillary loops. These alterations are homogenous with little variation between glomeruli. The mesangium is generally normal or slightly proliferated. Glomerular basal thickening is variable in intensity depending on the disease severity and evolution stage (25).

When there are at least two cell layers occupying the glomerular extracapillary region, the anatomical aspect is defined as glomerular crescent. These layers may partially or totally occupy Bowman's capsule, obliterating the capillary tuft with high or low intensity. They may be cellular (cellular crescent), fibrocellular (fibrocellular crescent), or fibrous (fibrous crescent). Glomerular involvement can be segmental or global (2).

Membranoproliferative glomerulonephritis is also called mesangial capillary glomerulonephritis. Histological involvement is characterized by pronounced abnormalities in the mesangial and glomerular capillary loop regions (12). 
Renal histopathology presents many different lesions attributed to leishmaniasis, including an irregular increase in the glomerular basal membrane, mesangial matrix proliferation (22), and signs of membranoproliferative glomerulonephritis (1).

Visceral leishmaniasis shows expansion and mesangial hypercellularity of varying intensity and, in some cases, focal proliferative glomerulonephritis. Mild to moderate interstitial nephritis is frequent (13).

In naturally infected dogs, renal involvement was reported as a natural sequela, and the renal lesion is characterized by immunologically mediated glomerular and tubular injury (20).

In a study with 55 naturally infected VL positive dogs, histopathological analysis showed 2 dogs without lesions, 53 with interstitial and tubular alterations, and 46 with glomerular alterations. The alterations were focal segmental glomerulosclerosis $(n=9)$, mesangial proliferative glomerulonephritis $(n=17)$, membranoproliferative glomerulonephritis $(n=18)$, crescentic glomerulonephritis $(n=1)$, and chronic glomerulonephritis $(n=1)$. Integral amastigote forms of Leishmania in the kidneys were not found (6).

The circulating immune complexes found in man with and without clinical renal involvement suggest that the glomerular injury may be related to antigen primary deposition in the glomerulus and subsequent in situ formation of immune complexes (8).

The mechanism of interstitial nephritis in human leishmaniasis is as yet unknown. Nevertheless, the finding of tubular basement membrane and interstitial deposition of immunoglobulins and complement supports the hypothesis that immunological mechanisms may be related to Leishmania infantum infection (20).

Presence of specific protozoan antigenic material in the glomeruli of VL patients has not been documented (13). Identification of the etiological agent in renal histological studies is not common (16).

Leishmaniasis is known to induce renal alteration, which is a major factor in understanding the pathogenic mechanisms of the disease. The objective of this study was to evaluate clinical, laboratory (renal function and blood cell count) and renal histopathological findings in canine VL. 


\section{MATERIALS AND METHODS}

Seventy-three dogs of different breeds, ages, and sexes, caught by the Center for Zoonosis Control in Teresina, Piauí State, between January and March 2002, were evaluated. They were all subjected to enzyme-linked immunosorbent assay and indirect immunofluorescence test. Fifty-one dogs were seropositive for VL. They were distributed into two groups.

The case group consisted of $34 \mathrm{VL}$ seropositive dogs with clinical manifestation of the disease. The control group consisted of $17 \mathrm{VL}$ seropositive dogs without any clinical signs of the disease at physical examination.

The animals were subjected to physical and complementary examinations, which included blood cell count and serum biochemical determination (urea and creatinine). After this, they were subjected to euthanasia, and renal parenchyma fragments were collected for histopathology.

Renal fragments were prepared by the usual histological techniques and stained with hematoxylin-eosin (HE) and periodic acid-Schiff (PAS).

\section{Statistical Analysis}

Groups were compared by Student's $t$-test and Fisher's exact test (complete blood count and renal function). Results were analyzed using the "Statistical Analysis System" (SAS) program. Clinical and histopathological parameters were analyzed by frequency of occurrence.

\section{RESULTS}

Control animals (asymptomatic VL seropositive) were within normal patterns at physical examination.

The most frequent clinical signs in symptomatic VL seropositive animals (case group) were lymph node hypertrophy (85.29\%), eye secretion (20.59\%), and cachexia (17.65\%) (Figure 1).

The most frequent skin lesions were: ulcers (35.29\%), ear extremity wounds (26.47\%), diffuse alopecia (23.53\%), periocular alopecia, onychogryphosis, and hair opacity (20.59\%) (Figure 2).

Mean erythrogram values for both groups are shown in Table 1. Erythrocyte, hemoglobin, and hematocrit values were below normal in case-group animals. Student's $t$-test was significant between groups $(p<0.01)$. 
The individual erythrogram evaluation showed 19 case-group (55.88\%) and 2 control-group animals (11.76\%) with anemia. Fisher's exact test was significant between groups $(\mathrm{p}<0.01)$ (Table 4).

Blood smear evaluation did not show amastigote forms of Leishmania or any other intra or extracellular parasite species in neither group.

Mean leukogram values for both groups showed high rod neutrophil count. Other variables were within normal limits (Table 2).

Individual leukogram evaluation showed that 7 animals of the case group (20.59\%) and 3 of the control group (17.65\%) had leukocytosis. Leukopenia was found in one case-group animal (2.94\%). There was no significant difference between groups by Fisher's exact test for leukocytosis and leukopenia (Table 4).

Out of the 7 case-group animals with leukocytosis, two had myiasis and associated infection; one had suppurative otitis; and one showed pyodermatitis. All other animals with leukocytosis did not show anything worthy of note.

Monocyte showed a significant difference $(p<0.05)$ and the mean values for both groups were within normal limits. Four case-group animals (11.76\%) had monocytosis (Table 2).

Mean platelet counts for both groups were within normal limits but with high standard deviations (Table 2). Thrombocytopenia was seen in 10 animals of the case group (29.41\%) and in 10 of the control group (58.82\%).

Table 3 shows means and standard deviations of serum concentrations for creatinine and urea of symptomatic and asymptomatic nonazotemic VL seropositive dogs; means were within normal limits with no significant difference between groups.

Individual evaluation showed that two case-group animals (5.88\%) had azotemia. One animal presented $3.96 \mathrm{mg} / \mathrm{dl}$ creatinine and $279.12 \mathrm{mg} / \mathrm{dl}$ urea; the others showed $1.58 \mathrm{mg} / \mathrm{dl} \mathrm{creatinine} \mathrm{and} 77.87 \mathrm{mg} / \mathrm{dl}$ urea.

Fisher's exact test showed no significant difference for azotemia between groups (Table 4).

Renal histopathological evaluation showed interstitial mononuclear inflammatory infiltrate varying from discrete and diffuse to severe for both groups (Figure 3B), $70.59 \%(n=24)$ in the case group and $64.70 \%(n=11)$ in the control group. There was no significant difference between groups (Table 5).

The case group showed 11 (32.35\%) animals with tubular hydropic degeneration, 4 $(11.76 \%)$ with cylindruria, $5(14.70 \%)$ with tubular vacuolization, 5 (14.70\%) with 
interstitial fibrosis, and 1 (2.94\%) with tubular necrosis. The control group presented $2(11.76 \%)$ animals with hydropic degeneration, 2 (11.76\%) with tubular vacuolization, 1 (5.88\%) with cylindruria, 1 (5.88\%) with interstitial fibrosis, and 1 (5.88\%) with medullar calcification.

Membranoproliferative glomerulonephritis (Figure 3A) was seen in $61.76 \%(n=21)$ case and $17.65 \%(n=3)$ control-group animals, with a significant difference (Table 5).

There was a significant difference for mesangial proliferative glomerulonephritis between both groups: $32.35 \%(n=11)$ case and $64.70 \%(n=11)$ control.

Based on the WHO glomerulonephritis classification criteria, histopathology of renal tissue samples produced the following diagnosis: focal segmental sclerosis, total sclerosis (Figure 3D), membranoproliferative glomerulonephritis, mesangial proliferative glomerulonephritis and membranous glomerulonephritis.

The renal histopathological section of one case-group dog, stained with HE, showed macrophages filled with amastigote forms of Leishmania $\mathrm{sp}$ in the interstitial multifocal mononuclear inflammatory infiltrate (Figure 3C). This section also showed areas of glomerular edema, moderate hydropic degeneration of the tubule, moderate mononuclear pyelitis and cylindruria.

Two case-group animals had azotemia associated with renal histological alterations.

\section{Clinical abnormalities}
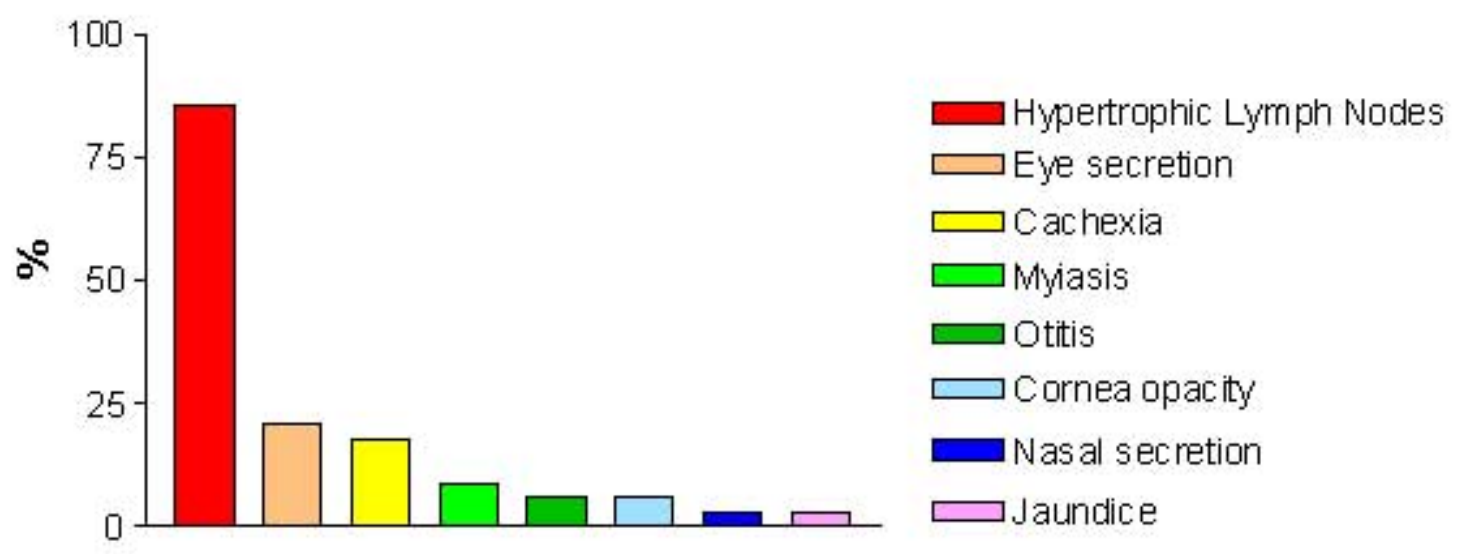

Figure 1: Frequency (\%) of clinical abnormalities in symptomatic VL seropositive dogs ( $n=34$ ) from Teresina, Piauí State, Brazil, 2002. 


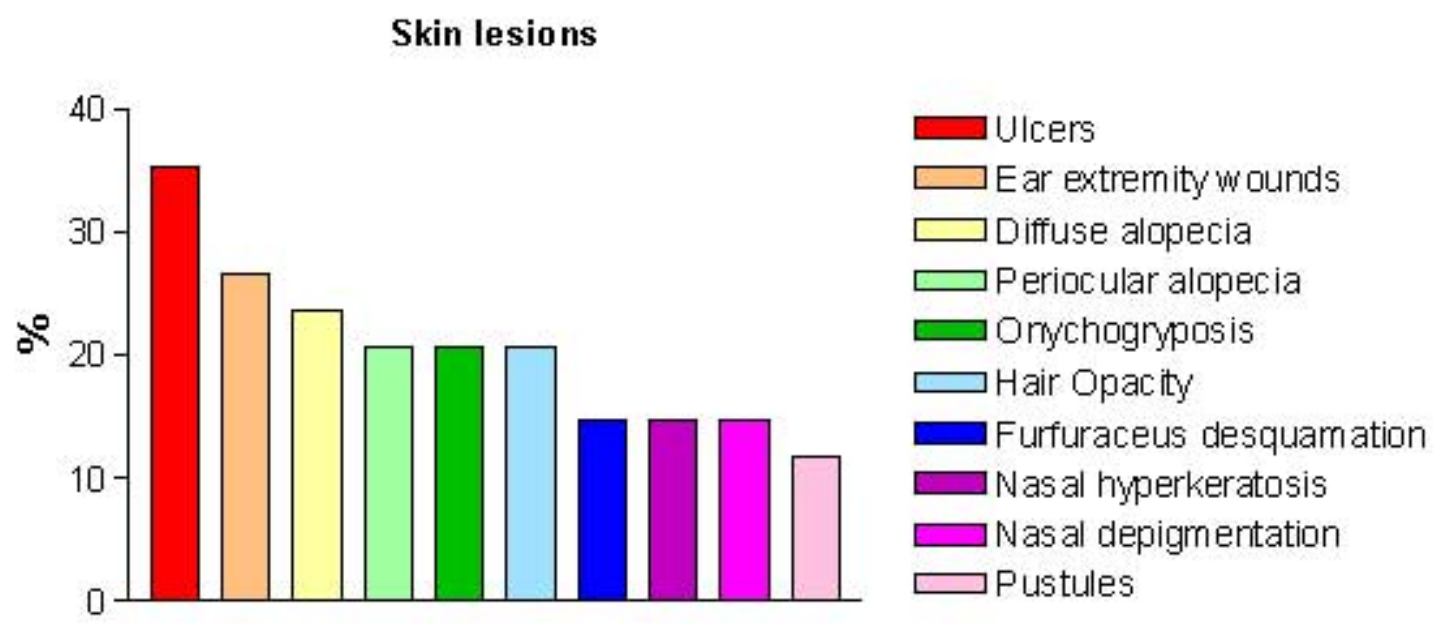

Figure 2: Frequency (\%) of different skin lesions in symptomatic VL seropositive dogs ( $n=34)$ from Teresina, Piauí State, Brazil, 2002.

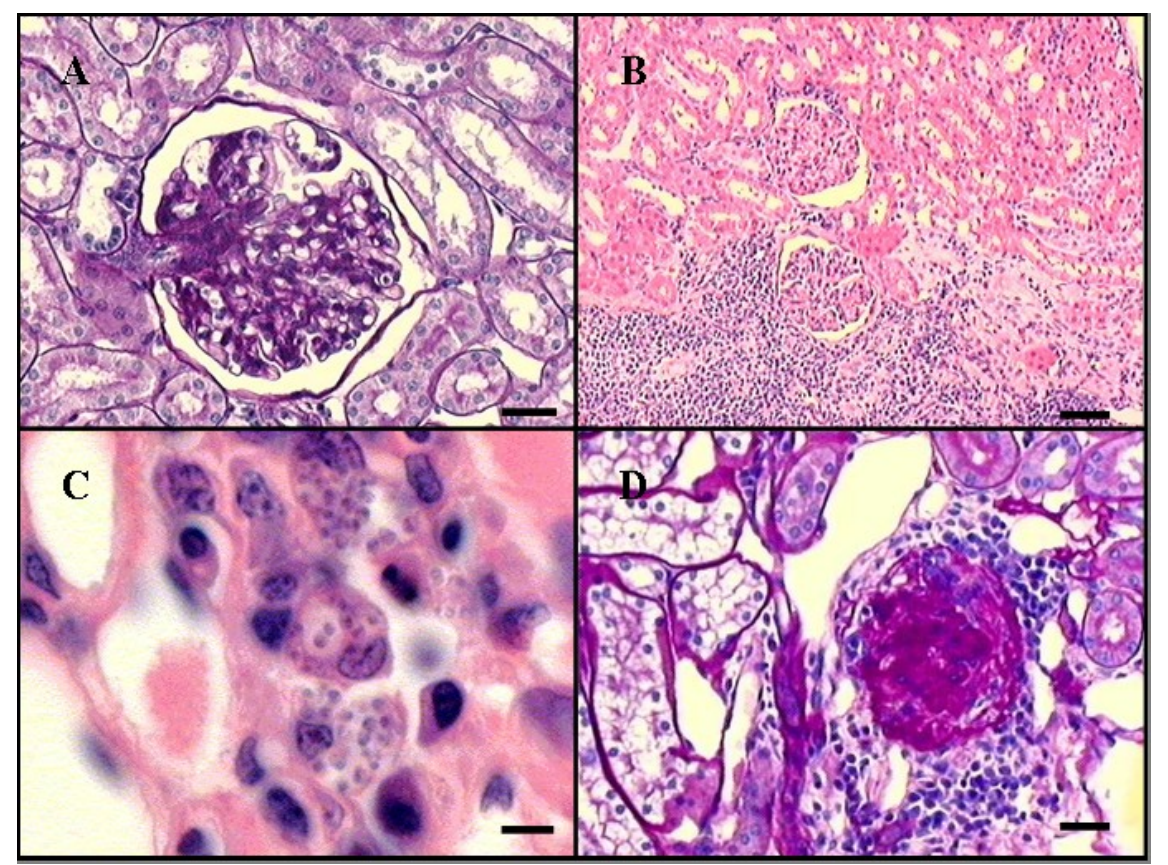

Figure 3: Microphotograph of a renal lesion in symptomatic VL seropositive dogs. A: Membranoproliferative glomerulonephritis. PAS staining. Bar: $12.5 \mu \mathrm{m}$. B: Inflammatory mononuclear infiltrate. HE staining. Bar: $25 \mu \mathrm{m} \mathrm{C}$ : Macrophages with amastigote forms of Leishmania. HE staining. Bar: $5 \mu \mathrm{m}$. D: Total glomerular sclerosis. PAS staining. Bar: $25 \mu \mathrm{m}$. 
Table 1: Mean and standard deviations of erythrometric variables of symptomatic $(n=34)$ and asymptomatic $(n=17)$ VL seropositive dogs from Teresina, Piauí State, Brazil, 2002.

\begin{tabular}{lccc}
\hline Variable & Reference Value & Symptomatic Dogs & Asymptomatic Dogs \\
\hline Erythrocytes $\left(\times 10^{6} / \mu \mathrm{l}\right)$ & $5.5-8.5$ & $5.20 \pm 1.54^{\mathrm{a}}$ & $6.39 \pm 0.93^{\mathrm{b}}$ \\
Hemoglobin $(\mathrm{g} / \mathrm{dl})$ & $12-18$ & $10.56 \pm 3.18^{\mathrm{a}}$ & $12.91 \pm 1.87^{\mathrm{b}}$ \\
Hematocrit $(\%)$ & $37-55$ & $32.74 \pm 10.07^{\mathrm{a}}$ & $40.32 \pm 5.78^{\mathrm{b}}$ \\
MCV (fL) & $60-77$ & $62.91 \pm 5.26^{\mathrm{a}}$ & $63.35 \pm 6.37^{\mathrm{a}}$ \\
MCHC (g/dl) & $31-34$ & $2.35 \pm 1.26^{\mathrm{a}}$ & $32.05 \pm 0.72^{\mathrm{a}}$ \\
\hline
\end{tabular}

Same letters in the same line does not show significant difference by Student's $t$-test at $5 \%$ probability; $\mathrm{MCV}=$ Mean corpuscular volume; $\mathrm{MCHC}=$ mean corpuscular hemoglobin concentration.

Table 2: Mean and standard deviations of leukometric variables for symptomatic $(n=34)$ and asymptomatic $(n=17)$ VL seropositive dogs from Teresina, Piauí State, Brazil, 2002.

\begin{tabular}{lccc}
\hline Variable & Reference Value & Symptomatic Dogs & Asymptomatic Dogs \\
\hline Leukocytes $\left(\times 10^{3} / \mu \mathrm{l}\right)$ & $6-18$ & $14.26 \pm 9.92^{\mathrm{a}}$ & $13.90 \pm 5.77^{\mathrm{a}}$ \\
Basophils $\left(\mathrm{x} 10^{3} / \mu \mathrm{l}\right)$ & $0-0$ & $0.015 \pm 0.043^{\mathrm{a}}$ & $0.044 \pm 0.135^{\mathrm{a}}$ \\
Eosinophils $\left(\mathrm{x} 10^{3} / \mu \mathrm{l}\right)$ & $0.12-1.8$ & $0.750 \pm 0.668^{\mathrm{a}}$ & $0.788 \pm 0.541^{\mathrm{a}}$ \\
Rod Neutrophils $\left(\mathrm{x} 10^{3} / \mu \mathrm{l}\right)$ & $0-0.5$ & $0.635 \pm 1.243^{\mathrm{a}}$ & $0.647 \pm 0.504^{\mathrm{a}}$ \\
Segmented Neutrophils & $3.6-13.8$ & $9.492 \pm 8.038^{\mathrm{a}}$ & $8.946 \pm 6.321^{\mathrm{a}}$ \\
$\left(\mathrm{x} 10^{3} / \mu \mathrm{l}\right)$ & & & \\
Lymphocytes $\left(\mathrm{x} 10^{3} / \mu \mathrm{l}\right)$ & $0.72-5.4$ & $2.368 \pm 1.490^{\mathrm{a}}$ & $3.053 \pm 1.752^{\mathrm{a}}$ \\
Monocytes $\left(\mathrm{x} 10^{3} / \mu \mathrm{l}\right)$ & $0.18-1.8$ & $0.856 \pm 0.986^{\mathrm{a}}$ & $0.430 \pm 0.383^{\mathrm{b}}$ \\
Platelets $\left(\mathrm{x} 10^{3} / \mu \mathrm{l}\right)$ & $180-400$ & $271 \pm 146^{\mathrm{a}}$ & $286 \pm 223^{\mathrm{a}}$ \\
\hline Same letters $\mathrm{in}$ (he & & &
\end{tabular}

Same letters in the same line does not show significant difference by Student's $t$-test at $5 \%$ probability.

Table 3: Mean and standard deviations of serum creatinine and urea in symptomatic $(n=32)$ and asymptomatic $(n=17)$ nonazotemic VL seropositive dogs from Teresina, Piauí State, Brazil, 2002.

\begin{tabular}{lccc}
\hline Variable & Reference Value & Symptomatic Dogs & Asymptomatic Dogs \\
\hline Creatinine $(\mathrm{mg} / \mathrm{dl})$ & $0.5-1.5$ & $1.02 \pm 0.20^{\mathrm{a}}$ & $1.10 \pm 0.13^{\mathrm{a}}$ \\
Urea $(\mathrm{mg} / \mathrm{dl})$ & $15-65$ & $28.01 \pm 9.44^{\mathrm{a}}$ & $22.59 \pm 8.21^{\mathrm{a}}$
\end{tabular}


Table 4: Complete blood count and serum biochemistry in symptomatic $(n=34)$ and asymptomatic $(n=17)$ nonazotemic VL seropositive dogs from Teresina, Piauí State, Brazil, 2002.

\begin{tabular}{|c|c|c|c|c|}
\hline \multirow[t]{2}{*}{ Diagnosis } & \multicolumn{2}{|c|}{ Symptomatic Dogs } & \multicolumn{2}{|c|}{ Asymptomatic Dogs } \\
\hline & $\mathrm{N}^{\mathrm{O}}$ & $\%$ & $\mathrm{~N}^{\mathrm{O}}$ & $\%$ \\
\hline Anemia & $19^{a}$ & 55.88 & $2^{b}$ & 11.76 \\
\hline Leukocytosis & $7^{\mathrm{a}}$ & 20.59 & $3^{a}$ & 17.65 \\
\hline Leukopenia & $1^{\mathrm{a}}$ & 2.94 & $0^{a}$ & 0 \\
\hline Thrombocytopenia & $10^{a}$ & 29.41 & $10^{\mathrm{a}}$ & 58.82 \\
\hline Azotemia & $2^{a}$ & 5.88 & $0^{a}$ & 0 \\
\hline \multicolumn{5}{|c|}{$\begin{array}{l}\text { Table 5: Result of renal histological evaluations of symptomatic }(n=34) \text { and } \\
\text { asymptomatic }(n=17) \text { nonazotemic VL seropositive dogs from Teresina, Piauí State, } \\
\text { Brazil, } 2002 \text {. }\end{array}$} \\
\hline \multirow[t]{2}{*}{ Diagnosis } & \multicolumn{2}{|c|}{ Symptomatic Dogs } & \multicolumn{2}{|c|}{ Asymptomatic Dogs } \\
\hline & $\mathrm{N}^{\mathrm{O}}$ & $\%$ & $\mathrm{~N}^{\mathrm{O}}$ & $\%$ \\
\hline MemPGN & $21^{a}$ & 61.76 & $3^{b}$ & 17.65 \\
\hline MesPGN & $11^{\mathrm{a}}$ & 32.35 & $11^{b}$ & 64.70 \\
\hline Int. Nephritis & $24^{a}$ & 70.59 & $11^{a}$ & 64.70 \\
\hline
\end{tabular}

Same letters in the same line does not show significant difference by Fisher's exact test at 5\% probability; MemPGN = membranoproliferative glomerulonephritis; MesPGN = mesangial proliferative glomerulonephritis; Int. Nephritis = interstitial nephritis.

\section{DISCUSSION}

In this study, clinical signs in symptomatic VL seropositive dogs showed alterations compatible with the classical clinical picture of $\operatorname{VL}(20,21)$. Leishmaniasis clinical manifestations depend on interactions between the virulence characteristics of the infecting Leishmania species and the host immune response (19). Symptomatic (case) dogs showed different types and degrees of clinical symptoms, such as lymph node hypertrophy (85.29\%), eye secretion (20.59\%), and cachexia (17.65\%).

Clinical evaluation of cutaneous lesions showed higher occurrence of ulcers (35.29\%), wounds on ear extremities (26.47\%), diffuse alopecia (23.53\%), periocular alopecia, onychogryphosis and hair opacity (20.59\%), corroborating with other authors (21). 
Anemia is one of the symptoms that appear with the disease after an incubation period ranging from one month to several years. It was seen in $55.88 \%$ of symptomatic animals. The mean number of erythrocytes for symptomatic dogs was below the reference levels. There was a significant difference for erythrocytes, hemoglobin, hematocrit, and anemia in both groups. This research demonstrated that anemia is directly related to VL symptomatology. Anemia occurs due to blood loss, red blood cell lysis, or to decreased erythropoiesis resulting from medullar aplasia or hypoplasia (10). In a study with 150 dogs naturally infected with VL, normocytic normochromic anemia occurred in $60 \%$ of the animals (5). These data agree with other investigations (7).

We found leukocytosis in $20.59 \%$ symptomatic and $17.65 \%$ asymptomatic animals. Student's $t$ - and Fisher's exact test showed no significant difference for leukocytes between groups and leukocytosis in both groups. In this research, four of the seven symptomatic animals with leukocytosis had bacterial infection.

Three of the four case-group animals with monocytosis had leukocytosis and neutrophilia. There was a significant difference between groups although means were normal. Monocytosis generally accompanies neutrophilia in purulent inflammation, granulomatous disease, necrosis, or hemolysis. One of the monocyte functions is phagocytosis of infectious agents (bacteria, rickettsia, fungi, protozoa, and viruses) (23). In VL, the etiological agent is rarely found in blood smear monocytes (24). This report showed that this hematological alteration was related to purulent inflammation (myiasis, suppurative otitis and pyodermatitis).

Mean platelet count was normal, but there was a marked standard deviation suggesting it was highly varied in symptomatic and asymptomatic animals. Student's $t$-test showed no significant difference. We observed the presence of thrombocytopenia in $29.41 \%$ symptomatic and $58.82 \%$ asymptomatic animals; Fisher's exact test showed no significant difference between groups. In a study with 95 leishmaniasis dogs, 50\% had thrombocytopenia (24); in another study with 150 naturally infected dogs, it was seen in $29.3 \%$ of the animals (5).

Alterations in platelet count in VL seropositive dogs were evaluated without ruling out the possibility of concomitant diseases such as ehrlichiosis, which also causes thrombocytopenia, considering that several animals presented tick infestation.

In this report, blood smear did not show intra or extracellular amastigote forms of Leishmania in any group. Amastigote forms of Leishmania donovani are rarely 
detected in neutrophils of dogs with the disseminated disease (23). Leishmania parasite was detected in the blood smear monocytes of one animal (24).

Serum concentrations of urea and creatinine were increased in two symptomatic animals (5.88\%); the others, both symptomatic and asymptomatic dogs, were within normal limits. The two azotemic animals showed membranoproliferative glomerulonephritis in the renal histopathological evaluation. Increase in urea, creatinine, proteinuria and hematuria concentrations is commonly seen in dogs with renal involvement (11). In a study with 50 human VL patients, 8.5\% showed increased blood urea and $16.3 \%$ showed increased creatinine (9). In another study with 10 infected dogs, seven showed increased serum urea, and three presented increased creatinine (17).

Histopathological evaluation revealed $70.59 \%(n=24)$ case and $64.70 \%(n=11)$ control-group animals with interstitial mononuclear inflammatory infiltrate; Fisher's exact test showed no significant difference between groups. Both groups also showed tubular hydropic degeneration, cylindruria, tubular vacuolization, interstitial fibrosis, and tubular necrosis. In a study with 55 VL dogs, interstitial inflammatory alterations were seen in $78.2 \%$ (6). A renal histological study on 34 dogs naturally infected by $L$. infantum showed that 31 had interstitial and tubular alterations. The interstitial nephritis mechanism in human leishmaniasis is still unknown, however the findings of immunoglobulin and complement deposits on the tubular basal membrane and interstitium supports the hypothesis that immunological mechanisms may be related to $L$. infantum infection. Interstitial and glomerular nephritis may result from immunologically mediated injury (20).

Membranoproliferative glomerulonephritis was present in $61.76 \%(n=21)$ case group and $17.65 \%(n=3)$ controls. Mesangial proliferative glomerulonephritis was observed in $32.35 \%(n=11)$ case and $64.70 \%(n=11)$ control animals. There was significant difference between both types of proliferative glomerulonephritis between groups. In this work, we observed that the case group showed higher frequency of kidney membranoproliferative glomerulonephritis, while in the control group mesangial proliferative glomerulonephritis in the kidney was more frequent. This suggests that, in canine VL, renal lesion is the earliest manifestation; regardless of physical examination signs, the kidneys were frequently compromised. Diagnosis of different morphological types can indicate that renal alterations may result from individual 
differences in the immune response of different hosts or from alterations in the same animal during the disease evolution (6).

Studies using a similar methodology to classify glomerulonephritis showed $30.9 \%$ and $32.7 \%$ incidence of mesangial proliferative and membranoproliferative glomerulonephritis, respectively (6). In a renal histological study of 34 dogs naturally infected by $L$. infantum, all animals had glomerular disease (20). Similarly to man, renal lesions in canine VL are predominantly located in the cortical region (8).

Some authors did not find a positive correlation between the circulating immune complexes and the immune complexes in glomerulonephritis (9).

We identified amastigote forms of Leishmania inside macrophages in the renal tissue in the inflammatory infiltrate of one symptomatic seropositive dog; this is not frequent and was not found in literature on natural or experimental infection.

Renal histopathological evaluation of the two azotemic animals showed membranoproliferative glomerulonephritis as one of the alterations, demonstrating renal azotemia.

Briefly, our data demonstrate that azotemia is associated with canine visceral leishmaniasis. Interstitial nephritis is common in symptomatic and asymptomatic VL seropositive dogs. Membranoproliferative glomerulonephritis is frequent in symptomatic VL seropositive dogs; on the other hand, mesangial proliferative glomerulonephritis is more frequent in asymptomatic VL seropositive dogs.

\section{ACKNOWLEDGMENTS}

The authors thank The State of São Paulo Research Foundation (FAPESP), for financial support; the Center for Zoonosis Control in Teresina, Piauí State, for donating the animals; and Maria Inês Yamazaki de Campos and Francisca de Assis Ardisson, for preparing the histological sections.

\section{REFERENCES}

1 AGU WE., FARRELL JP., SOULSBY EJL. Proliferative glomerulonephritis in experimental Leishmania donovani infection of the golden hamster. Comp. Immunol. Microbiol. Infect. Dis., 1981, 4, 353-68.

2 ALVES MAR. Glomerulonefrite crescêntica. In: SOARES V., ALVES MAR., BARROS RT. Glomerulopatias: patogenia, clínica e tratamento. São Paulo: Sarvier, 1999: 118-27. 
3 BRASIL. Ministério da Saúde. Leishmaniose visceral. In: Guia brasileiro de vigilância epidemiológica. 5. ed. Brasília: Fundação Nacional de Saúde, 1998. 1-7.

4 CHURG J., BERNSTEIN J., GLASSOCK RJ. Renal disease: classification and atlas of glomerular disease. 2. ed. New York: Igaku-shoin, 1985. 541p.

5 CIARAMElla P., Oliva G., DE LUNA R., GRAdONI L., AMBROSIO R., CORTESE L., SCALONE A., PERSECHINO A. A retrospective clinical study of canine leishmaniasis in 150 dogs naturally infected by Leishmania infantum. Vet. Rec., 1997, 141, 539-43.

6 COSTA FAL. Patologia e imunopatogenia da nefropatia da leishmaniose visceral canina. São Paulo: Universidade de São Paulo, Faculdade de Medicina Veterinária e Zootecnia, 2001. 129p. [Thesis - Doctorade]

7 DEDET JP. Les leishmaniosis en Afrique du Nord. Bull. Inst. Pasteur, 1979, 77, 4982.

8 DUARTE MIS., SILVA MRR., GOTO H., NICODEMO EL., AMATO NETO V. Interstitial nephritis in human kala-azar. Trans. R. Soc. Trop. Med. Hyg., 1983, 77, 531-7.

9 DUTRA M., MARTINELLI R., CARVALHO EM., RODRIGUES LE., BRITO E., ROCHA H. Renal involvement in visceral leishmaniasis. Am. J. Kidney Dis., 1985, 6, 22-7.

10 FEITOSA MM., IKEDA FA., LUVIZOTTO MCR., PERRI SHV. Aspectos clínicos de cães com leishmaniose visceral no município de Araçatuba - São Paulo (Brasil). Clín. Vet., 2000, 5, 36-44.

11 GRAUER GF., DIBARTOLA SP. Afecções glomerulares. In: ETTINGER SJ., FELDMAN EC. Tratado de medicina interna veterinária: moléstia do cão e do gato. 4. ed. São Paulo: Manole, 1997: 2432-52.

12 KIRSZTAJN GM. Glomerulonefrite membranoproliferativa. In: SOARES V., ALVES MAR., BARROS RT. Glomerulopatias: patogenia, clínica e tratamento. São Paulo: Sarvier, 1999: 92-9.

13 MARTINELLI R., SILVEIRA MA., ROCHA H. Glomerulonefrites associadas a infestações parasitárias. In: SOARES V., ALVES MAR., BARROS RT. Glomerulopatias: patogenia, clínica e tratamento. São Paulo: Sarvier, 1999: 206-13. 
14 MARZOCHI MCA., COUTINHO SG., SABROZA PC., SOUZA MA., SOUZA PP., TOLEDO LM., RANGEL FILHO FB. Leishmaniose visceral canina no Rio de Janeiro - Brasil. Cad. Saúde Públ., 1985, 1, 432-46.

15 MORENO P., LUCENA R., GINEL PJ. Evaluation of primary haemostasis in canine leishmaniasis. Vet. Rec., 1998, 142, 81-3.

16 NICODEMO EL., DUARTE MIS., NICODEMO AC., AMATO NETO V. Aspectos clínico-laboratoriais da nefrite intersticial da leishmaniose visceral. Rev. Paul. Med., 1984, 102, 19-22.

17 NIETO CG., NAVARRETE I., HABELA MA., SERRANO F., RENDONDO E. Pathological changes in kidneys of dogs with natural Leishmania infection. Vet. Parasitol., 1992, 45, 33-47.

18 NOLI C. Leishmaniosis canina. Waltham Focus, 1999, 9, 16-24.

19 PEARSON RD., SOUSA AQ. Clinical spectrum of leishmaniasis. Clin. Infect. Dis., 1996, 22, 1-11.

20 POLI A., ABRAMO F., MANCIANTI F., NIGRO M., PIERI S., BIONDA A. Renal involvement in canine leishmaniasis: a light-microscopic, immunohistochemical and electron-microscopic study. Nephron, 1991, 57, 444-52.

21 SANTA ROSA ICA., OLIVEIRA ICS. Leishmaniose visceral: breve revisão sobre uma zoonose reemergente. Clín. Vet., 1997, 2, 24-8.

22 SARTORI A., OLIVEIRA AV., ROQUE-BARREIRA MC., ROSSI MA., CAMPOSNETO A. Immune complex glomerulonephritis in experimental kala-azar. Parasite Immunol., 1987, 9, 93-103.

23 SCHULTZE AE. Interpretation of canine leukocyte responses. In: FELDMAN BF., ZINKL JG., JAIN NC. Schalm's veterinary hematology. 5. ed. Philadelphia: Lippincott Williams \& Wilkins, 2000: 366-81.

24 SLAPPENDEL RJ. Canine leishmaniasis: a review based on 95 cases in the Netherlands. Vet. Quart., 1988, 10, 1-16.

25 SOARES V., VIERO RM. Glomerulonefrite membranosa. In: SOARES V., ALVES MAR., BARROS RT. Glomerulopatias: patogenia, clínica e tratamento. São Paulo: Sarvier, 1999: 66-86. 